MedieKultur | Journal of media and communication research | ISSN 1901-9726

Article - Open section

\title{
Factors enhancing learning possibilities in digital workshops
}

\section{Christian Kobbernagel}

MedieKultur 2014, 56, 170-190

Published by SMID | Society of Media researchers In Denmark | www.smid.dk The online version of this text can be found open access at www.mediekultur.dk

This article presents a study of processes supporting student learning possibilities in digital workshops planned and held at art museums in Denmark. The investigation aims to provide insights into factors enhancing learning possibilities, including the educator's dialogic performance, experiences of art, and perceived qualities of digital content creation processes in art museum education workshops. To address the research question of what conditional and processual factors can be said to support learning possibilities, a model was developed on the basis of fieldwork and theories of media education, art pedagogy and motivation. The model was then analyzed using structural equation modelling (SEM) on data collected $(n=502)$ after workshops in two museums. The results suggest that the dialogic performance of museum educators, a positive art experience and positive perceptions of working with digital media are factors that strongly support student participation and reflection - although to various degrees. The findings also show that, in cases in which students are disinterested and see little value in participating during the workshop, this amotivation is likely to be lower when their art experiences and their perceptions of the media production process are positive. 


\section{Introduction}

The main objective of this article is to present an empirical study of factors supporting learning in digital workshops at art museums. The study includes a survey of students' learning outcomes and perceptions of selected conditions for learning at two museums: ARKEN Museum of Modern Art and The National Gallery of Denmark. At these museums, digital workshops are designed to engage students in experiences of art and debates about exhibition themes. The workshops are planned as three-hour events during which students are guided around the exhibition and invited to discuss themes and issues communicated in the artworks. In one phase of the workshops, students are asked to create a small narrative using digital media tools to answer the questions raised in an assignment. The goal is to introduce students to how art can be viewed in different ways and to understand how it can communicate themes of a political, social or cultural kind. In these endeavors, the museums emphasize that art can be seen as an asset for developing young people's understanding of and engagement with public cultural and political debates (Burton, Horowitz, \& Abeles, 2000, p. 255).

It follows that the education departments of the museums are interested in evaluating how well this goal is achieved and in exploring the extent to which program conditions and inputs from educators can influence learning. In particular, the evaluation seeks to assess whether the strategy of educators' dialogic performance by inviting students to participate in a critical dialogue within the museum setting enhances their awareness of the potential of artworks to stimulate public debate. Is this dialogic approach of value for changing students' views about art? Furthermore, it is of interest to address the question of whether the processes of content creation support discussion and reflection within groups of students. Some of these questions have previously been asked and investigated by researchers utilizing a qualitative approach. These studies offer insights into individual and group learning by examining situated learning processes. Studies of this kind have provided more detailed knowledge of digital media use in art education by analyzing specific situations or by following a single group to investigate the communication and social interaction. For example, how students give voice to sculptures to bring them to life and thereby articulate what they imagine the sculpture would say (Illeris, 2009, pp. 22-24), or how mobile blogging platforms can help students to establish links between museum and school activities and learning (Pierroux, Krange, \& Sem, 2011). These studies do not, however, engage with the question of whether and how their results apply in other situations, or deal with the broader perspective.

In this context, the general perspective is taken to mean the analytical capacity to account for the influence of conditions and educator efforts across the workshops included in the study - not a universal generalization. To support this analysis, the present study establishes a conceptual model of factors and the relationships that are considered important to enhance learning possibilities, based on preliminary field work at the two museums and theories of media production in education, art gallery learning and motivation 
in learning. By clarifying concepts and students' understanding of them as shared social constructions (Rommetveit, 2003, p. 214), the study seeks to operationalize constructs and their measurement through the lens of latent variable theory (Borsboom, 2008) and scale construction (DeVellis, 2003).

After a description of the digital workshop, the article presents the preliminary fieldwork, and gives an account of the process of construct development, and the theoretical arguments for relations between constructs in the model. It is thereafter the regressionbased estimation of these relations that inform the analysis of impacts of conditional and process factors on learning possibilities. Data collection and analytical procedures for developing the model will then be elaborated; and, finally, the results and their implications for learning in digital workshops will be interpreted and discussed.

\section{The digital workshop}

The digital workshops are educational events organized by the departments of education at ARKEN and The National Gallery of Denmark. The workshops are aimed primarily at upper secondary school and high school students aged between 13 and 20 who visit the museums as part of their school curriculum or for a thematic project designed and planned by the school's teachers. In many cases, students continue to work with some aspect of the workshop subject matter when they return to school. Thus, the learning trajectory includes the full range of learning taking place in the museum/school nexus. The media used in the workshops studied here were either still digital photos with captions or audiopodcasts containing small narratives of a two-to-three minute duration, expressing student views on the topics discussed. Despite variations in working processes, the workshops all conform to a general scheme of three elements: 1) students are taken on a guided tour of the galleries during which topics of a political, social or cultural kind are discussed; 2) students are given a task linked to the theme or genre of the works viewed, involving group co-creation of a digital file in the form of recorded speech or a captioned photograph; and 3) a presentation on the end product is delivered in class, entailing a collective evaluation of the process of creating the content.

To explicate the work process by which students create content and engage in discussions, one of these still photo workshops will be described in more detail. In this instance, the educator invited students to share thoughts on the concept of national identity with reference to the artworks of Lise Harlev (My Own Country) and Johan T. Lundbye (A Danish Shore). ${ }^{1}$ After the gallery tour, a group of students created a digital photo to convey their interpretation of national identity. Initially, several photos were produced, and they then selected one they considered most representative of their views. In designing the photo motif, the group discussed the individuality of people and how they come to be united as a nation. They decided to form the Danish flag out of four red mattresses and placed a student on each of them. The idea was to illustrate the point that, although Danes as 
persons are individuals with varying lifestyles, affiliations and attitudes, the flag symbolizes unity. The group discussed how identity could be represented by facial characteristics and expressions, and they engaged in negotiations about which photo best visualized their ideas. Thus, ideas and interpretations of what it means for people to relate to a national identity were discussed, mediated by the process of visualization involved in creating a photograph.

\section{Fieldwork}

In order to establish a basis for selecting the most important factors related to learning, observations were conducted in the two museums, which provided notes about students' behavior and talk, and video-recordings were also made in selected phases of the workshops. The descriptive approach employed methods used in media ethnography and was informed by questions such as "what is done?" and "who says what?" (Schrøder, Drotner, Kline, \& Murray, 2003, p. 93). This fieldwork aimed to identify the most salient conditions for learning, as seen through the eyes of the students. The results reveal that an educator's style of communication by inviting student comments and an articulation of views, along with the process of working in groups, seemed to encourage participation. The observations also revealed that, in terms of commenting and posing questions, students mostly remained quiet and only participated to a limited degree in a dialogue with the educator. Some of this behavior can be seen as disinterest. For example, some were chatting in the background despite the educators' invitation to join the discussion. During the group work phase, students tended to engage with increased levels of attention; but, again, some seemed more occupied with extraneous social conversation and use of their mobile phones. In short, levels of concentration varied widely; and, in some cases, whole groups of students seemed disinterested. Furthermore, the interviews revealed that students did not view the outcomes of the workshop as learning. They saw the museum visit more in terms of an experience that, for some, changed their views about the usefulness of art, but they did not refer to this as learning. The educator's talk was considered important for reflection, but the students also expressed a wish to have had more time to explore the artworks themselves. Taken together, these initial findings made it possible to create a first draft of a model of constructs of important conditions and their relation to constructs of student behavior and learning outcomes.

\section{Theoretical understanding}

To scrutinize the meaning of constructs and their relations in the model, two bodies of theory were used. The first relates to the disciplines of art and media education (SeftonGreen \& Soep, 2007; Buhl 2005; Illeris, 2009; Drotner, 2008; Dysthe, 2002), while the second comes from psychology, focusing on the concepts of motivation (Ryan \& Deci, 2000) and 
reflection (Kember et al., 2000). The operationalization of constructs into measures rests on Andrew M. Ledbetter's understanding, referring to Rokeach (1968), of the influence of attitudes and orientations towards objects and behaviors. Attitude he sees as:

\section{a relatively enduring organization of beliefs around an object or situation predisposing one to respond in some preferential manner [...] with these beliefs possessing both cognitive and affective components. These affective/cognitive orientations, in turn, influence behavior toward the attitude object (Ledbetter et al., 2011, p. 29).}

Furthermore, the operationalization rests on Rommetveit's (2003) concept of shareholding in language. Rommetveit contends that people's understandings of concepts are both social and subjective and that parts of the meaning of concepts and words are shared across groups of people who are in some way related (2003, p. 214). In the present study, this idea of shared meaning of concepts is applied to the pattern of student responses to survey questions so the assumption is that indicator variables, for example, of the construct 'potential for further reflection' will produce a statistically reliable structure. The validity of these construct measures and their observed relationships, however, can only be seen as a construction (Markus, 2008, p. 61), and claims regarding impacts can, therefore, only be judged on the basis of some form of social constructionist view (Cherryholmes, 1988, p. 106).

Artworks and art museums offer a wealth of perspectives and messages about topics of central concern in public political or cultural discourse. Helene llleris, who has worked intensively with young people who visit and learn in museums, argues that the success of a young person's learning encounter with art tends to depend on four factors: the hook (or the artworks' capacity to capture their attention), otherness (defined as a visual or aesthetic appearance that is other than normal), meta-reflection (which refers to students' capacity to reflect on their own role as learners) and interaction (which means the process of articulating, sharing and rethinking the messages conveyed by art) (Illeris, 2005, p. 237). She maintains that learning processes in art museums are consolidated by inherent opportunities to reflect on abstract concepts, such as, for example, the adoption of different perspectives in viewing art (Illeris, 2009). Here, learning is understood as an awareness of analytical resources, but little is said about the diversity of students' attitudes, motivations, and emotional states when engaging with artworks. With regard to attitudes, Danish research has shown that some students feel alienated by the over-intellectualization of meanings in this context (Hjort \& Larsen, 2003; Bøje, Kampmann \& Larsen, 2005) and are, therefore, likely to disengage. The digital workshop aims in part to meet this challenge of motivating students insofar as the process of creative content production involves feelings of autonomy and competence while, at the same time, offering a work process that facilitates reflection about meaningful content (Peppler \& Kafai, 2007, p. 152). 


\section{Conceptual framework}

Taking the results of the preliminary fieldwork as a point of departure, a conceptual-theoretical model that includes a set of hypotheses was developed to organize the analyses formally (Figure 1).

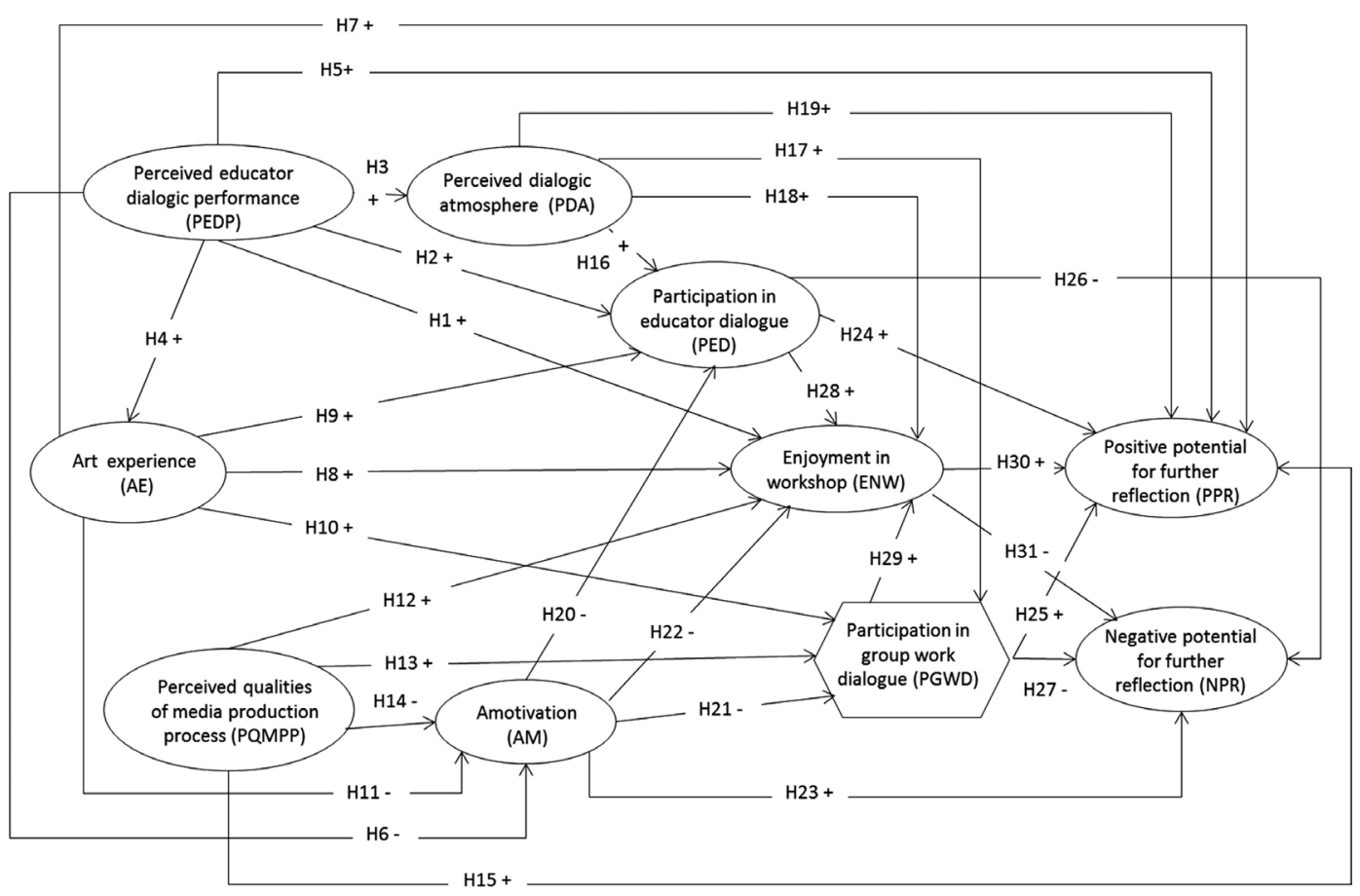

Figure 1 Conceptual model of factors enhancing learning possibilities

The model shows constructs in ovals and one hexagon (with name and abbreviation in parenthesis). In each oval and the hexagon, a set of indicators is chosen-partly, on the basis of fieldwork and interviews and, partly, on the basis of theory-to represent the construct in question. To reduce the complexity of Figure 1, these indicators are not shown. Each arrow denotes a statistical relationship that is chosen as a representation of links between the constructs (positive or negative in which negative indicates an assumed inverse relationship). For instance, art experience (AE), understood as the situational experience of artworks, is assumed to reduce amotivation, as proposed in H11. As shown in the figure, ten constructs are included in the model. On the left side of the model, the three conditional factors are shown, and their links to processual and outcome factors are depicted by arrows. Amotivation is incorporated as an important mediating factor, linking to participation and outcomes, along with the perceived dialogic atmosphere and overall enjoyment of the workshop. The idea of "potential for reflection" as an outcome seemed to describe students' actual behaviors and utterances insufficiently. This was because some students reported that they left the museum with little sense of meaning and no positive change in 
attitude towards art, hence it made sense to characterize this outcome separately, as negative with respect to learning (i.e., negative potential for further reflection (NPR)). Participation is theorized to encompass listening and talking but also reflective thinking, following Olga Dysthe's concept of inner dialogue (Dysthe, 1999, p. 40), and to be a central factor both during the dialogue with the educator and in the phase in which students work in groups.

In order to operationalize the conceptual framework, latent variable theory is applied and a model built with a reflective measurement perspective with one exception in the participation construct, which is specified as formative due to the nature of the construct being behavior (Diamantopoulos \& Winklhofer, 2001; Kline, 2010, p. 280). The statistical entities or latent variables are analytical operators denoting the meaning spaces shared by the respondents (Rommetveit, 2003, p. 211). The relationships between constructs are conceived as structural elements of the discourse on learning in art museum digital workshops. This discourse is explicated through the clarification of constructs and interpretation of their hypothesized relationships. This implies that the theorized model introduce a certain simplified perspective. The directions in construct relationships are chosen based on the fieldwork results, which suggested that the context of the digital workshop and art museum visit involves certain roles and behaviors of actors (i.e., it is the educator who plans, organizes and takes the initiative). In the next section, the meaning of construct relations will be discussed with reference to three types of factors: conditional, process, and outcome.

\section{Conditional factors}

It is apparent that the art educator plays a central role as initiator and organizer of events. As already argued, dialogic communication is important for engaging students because, as noted by Dysthe (2003), dialogue in teaching practice involves a set of qualities to engage participants in conversation. In education, she contends, students will tend to participate if the educator performs well in fostering this conversation, as indexed by the construct "perceived educator dialogic performance" (PEDP), which relates to the educator's skill in establishing a dialogue by building on turn-taking, acceptance of the equal legitimacy of opinions, and enabling multi-voicedness (Dysthe, 2002, p. 342). Particularly in the context of the art gallery, authentic questioning - the educator's handling of student contributions to prompt further conversation-is crucial. When the educator creates an atmosphere that makes everyone feel welcome, invites all to participate, demonstrates interest in student opinions and uses responses purposefully, it is assumed that students will perceive a "positive dialogic atmosphere" (PDA). This, in turn, supports "participation in educator dialogue" (PED), and it is likely that PDA impacts students' overall "enjoyment of the workshop" (ENW) (Lumby, 2010). Enjoyment in this context is taken to be indicated by feelings of pleasure, excitement and having fun (Ryan \& Deci, 2000, p. 56). When students evaluate an educator's communicative behavior as positive with respect to dialogue, their motiva- 
tion tends to increase (Ellis, 2004, p. 14), and students are more likely to learn (Goodboy \& Myers, 2008). Moreover, the work of Goodboy, Martin and Bolkan (2009, p. 379) has shown that, when students experience a positive social environment, this impacts favorably on learning, and so it can be assumed that students' evaluations of educator dialogic performance will have a positive impact on "positive potential for further reflection" (PPR). Finally, a young person's experience of art will be affected by the feeling that any interpretation of an artwork's meaning is legitimate (Hjort \& Larsen, 2003, p. 9). When the educator's communicative behavior includes an appreciation of students' opinions, it is more likely that students will approach art with an open mind; and, consequently, their experiences of artwork will be positive (AE). Based on these accounts of the educator's role, the formal hypotheses $\mathrm{H} 1, \mathrm{H} 2, \mathrm{H} 3, \mathrm{H} 4$ and $\mathrm{H} 5$ were incorporated in the conceptual model.

The second important condition for learning is the experience of art itself. Viewing spectacular motifs in paintings that challenge preconceptions of normality or encountering the large, colorful artworks housed in art museums are central elements in the experience of art (Illeris, 2007). Art experience is a state of heightened awareness (Pelowski \& Akiba, 2011, p. 81), evoking curiosity and sparking a desire for more information, thereby motivating the viewer to think and to pose questions such as what, how, and why. In the present framework, art experience (AE) is taken to be indicated by felt situational interest, attention, and a feeling of wanting to know more. As $A E$ is associated with interest and, therefore, with a disposition to action (Ganger, 2006, p. 63), it is hypothesized that $A E$ relates both to participation in the educator dialogue (PED) and to participation in group work discussions (PGWD), as well as to the overall enjoyment of the workshop (ENW). Furthermore, a positive art experience $\mathrm{AE}$ is hypothesized also to relate directly to PPR. On this basis, hypotheses $\mathrm{H} 7, \mathrm{H} 8, \mathrm{H} 9$, and $\mathrm{H} 10$ were added to the model.

The third condition for learning concerns the media production phase in which students work with digital media in a regulated, free-choice environment to complete a group task and, then, discuss the meanings and interpretations of the artworks or theme with which they choose to work. This process yields feelings of engagement (Erstad \& Gilje, 2008, p. 222), an environment that encourages imagination and feelings of freedom to express personal views (Yardi, 2008, p. 107). All of these traits combined are assumed to be supportive of the discussion and negotiation of content. The proposed construct is, therefore, labeled "perceived qualities of the media production process" (PQMPP). During this process, learning possibilities are linked to formulating and giving voice to interpretations and meanings and to the development of personal opinions (Drotner, 2008, p. 169). That is, an exchange of views among peers fosters reflection and, potentially, the attainment of new knowledge (Sinker, 2000, p. 208). For these reasons and because content creation of both photos and audio podcasts embraces working with several modalities (Considine, Horton, \& Moorman, 2009, p. 473), it is hypothesized that perceptions of this environment will support participation in group work discussions (PGWD), positive potential for reflection (PPR) and a sense of engagement leading to feelings of enjoyment of the workshop 
(ENW). These related constructs underpin the hypotheses $\mathrm{H} 12, \mathrm{H} 13$, and $\mathrm{H} 15$, as seen in the lower part of Figure 1.

\section{Process factors}

As previously described, student amotivation, as indicated by disinterest, disaffection and negative perceptions of value during activities (Ryan \& Deci, 2000, p. 59) was an important construct for understanding the responses of some groups of students. An awareness of amotivation is considered crucial for understanding the processes of learning in art museums (Mason \& McCarthy, 2006). This construct is, thus, regarded as one of the key process factors mediating the relationships outlined above. It is assumed that students' perception and evaluation of the three conditional factors (PEDP, AE, and PQMPP) relate negatively to amotivation (AM).

In other words, amotivation may evolve from thoughts of art as a complex and boring artefact that conveys little meaning (Mason \& McCarthy, 2006, p. 23), but this amotivation will decrease if students become curious about the artworks, if the educator shows an interest in them and encourages dialogue and if students perceive the process of content production positively. Hypotheses $\mathrm{H} 6, \mathrm{H} 11$ and $\mathrm{H} 14$ suggest that a positive evaluation of these conditions relates negatively to amotivation (AM): High degrees of AE, PEDP, and PQMPP are expected to relate to a low degree of $A M$. The mediating function of $A M$ is thereby construed as follows: If students evaluate AE positively, this is assumed to reduce amotivation, which, in turn, is expected to increase both the level of participation and the overall enjoyment of the workshop because students who feel less amotivated will tend to engage more and to enjoy the activities. This capacity of amotivation as an inverse mediator generates three more hypotheses: $\mathrm{H} 20, \mathrm{H} 21$ and $\mathrm{H} 22$. This role of amotivation as an inverse mediator is also expected to link to "negative potential for further reflection" (NPR); hypothesis $\mathrm{H} 23$ designates this possible negative dimension.

The second process factor theorized to support learning possibilities is the degree to which students perceive the atmosphere as positive and inclusive with respect to dialogue (PDA). In their reports of art gallery educational activities at five large art museums in Copenhagen, Hjort \& Larsen (2003, p. 18) and Bøje, Kampmann and Larsen (2005) are in accord with the view expressed above that, because some students tend to feel alienated by overly intellectual art discourse and overwhelmed by authoritative interpretations, educators should communicate to appreciate students' opinions and seek to encourage students to express their personal views. The framework, therefore, assumes that perceptions of this aspect of the communicative atmosphere will support learning outcomes through the level of participation in both educator dialogue (PED) and group work discussions (PGWD), which link to "positive potential for further reflection" (PPR) and overall enjoyment in the workshop (ENW). Hypotheses $\mathrm{H} 16, \mathrm{H} 17, \mathrm{H} 18$ and $\mathrm{H} 19$ are added to the model to represent the positive effects of students' perceptions of dialogic atmosphere. 
Student participation and reflection is central to the discourse around learning through art gallery educational initiatives because, as Helene Illeris proposes, social interactionspecifically, articulating opinions and rethinking the viewer position based on one's experience-is a key condition for enhancing learning (Illeris, 2005, p. 237). Putting experience into words is one point of access to the processes of accommodating and assimilating knowledge. Dysthe, as noted, goes one step further by arguing for both verbalized and non-verbalized conversation in social interaction, observing that dialogue includes an inner thinking process (Dysthe, 1999, p. 40). This position finds support in Mustapha and Rahman's more recent findings (2011), which describe four ways of participating in learning contexts, one of which is passive non-verbal participation. They argue that participatory behavior can involve attention, thinking, reflection and involvement, thus entailing possibilities for learning (Mustapha \& Rahman, 2011, p. 155). This is not a new idea, but such formulations of non-verbal behavior do help to clarify the meaning of "participation" in the context of digital workshops. In this regard, the two relevant constructs-participation in group work discussion (PGWD) and participation in educator dialogue (PED) - are assumed to relate directly to learning possibilities as well as the evaluation of the workshop as an enjoyable event (ENW). PED is central to the work of Illeris and Dysthe, but little is said about enjoyment. It is, however, assumed that dialogic communication entails pleasure to some degree. PGWD, as Lumby explains, is likely to be enjoyable because participation in group work involves social interaction among peers-in other words, working with friends in a collaborative process (Lumby, 2010, p. 256). Taken together, these ideas add four hypotheses to the model: $\mathrm{H} 24, \mathrm{H} 25, \mathrm{H} 28$, and $\mathrm{H} 29$.

Seen from the perspective of the museums' strategic aim of building relationships, any evaluation of the workshops must ask whether students enjoyed the visit (Gether, Søholt, Laursen, Tøndborg, Weber \& Sattrup, 2010). Overall enjoyment of the event increases the likelihood of students returning to the museum in the future, and, in the context of art-based learning, enjoyment can facilitate a change of attitude from disinterest to greater openness towards art (Illeris, 2005). For this reason, therefore, students' enjoyment is assumed to increase learning possibilities (Lumby, 2010). In this context, enjoyment of the workshop is indicated by feelings of pleasure, excitement and fun in taking part in the workshops, connecting more to immediate "state" emotions than to cumulative retrospective "trait" emotions. As Lumby explains, "trait emotions are built over time and refer retrospectively to cumulative experience in enjoying classes. State emotions are experienced in the present, the current enjoyment of a specific class. Emotional traits are therefore predicated on the persistent experience of particular emotional states" (Lumby, 2010, p. 250). On this basis, it is argued that positive student evaluations of the workshops are likely to increase positive potential for reflection (PPR) and, conversely, to decrease negative potential for reflection (NPR). Hypotheses $\mathrm{H} 30$ and $\mathrm{H} 31$ are, therefore, added to the conceptual model. 


\section{Outcome factors}

The operationalization of outcomes is informed by two constructs (without adopting them in full): "critical thinking disposition" (CTD) and "student approach to learning" (SAL). In respect of CTD, Nancy Lampert argues that "reflecting on multiple interpretations of subject matter is an aspect of critical thinking, so it stands to reason that engagement in critical and aesthetic inquiry fosters in art students a disposition to think critically" (Lampert, 2006, p. 216). Seen in this light, critical thinking is a form of preparedness for reflection in relevant situations. However, it seems unlikely that students could achieve this during a three-hour event. Therefore, it is more reasonable to see this as a potential capability for reflections on the exhibition. Whereas CTD refers more particularly to cognitive capacities, the concept of SAL deals with a totality of skills, intentions and motives (Diseth, 2007, p. 188; Kember, Biggs, \& Leung, 2004, p. 262), defined to capture what might be characterized as an "orientation towards learning". One component of SAL relates to educational conditions: This is not included in the present framework because the outcome factors refer to how students perceive their experience of learning.

Lumby shows that students who are active often report that they achieved something during the program, and this is also likely to be the case when participation includes both verbal and non-verbal dialogue (Lumby, 2010, p. 258). Outcome factors are defined as the student's evaluation of learning possibilities, indicated by a sense of meaningfulness during the workshop, a recognition that viewing and experiencing art also depends on the viewer's perspective, an intention to use the content in the future and a changed view of art. As some students, as noted above, seem to remain disinterested, it is meaningful to conceive of the outcome in two ways: a negative way, entailing a degree of rejection of the content, and a positive way, entailing a degree of accommodation of the content. The case of rejection is discussed by Illeris, but it is unclear whether this state affords any potential for learning (Illeris, 2005, p. 239). Despite this possible over-simplification, PPR and NPR facilitate the use of the model to evaluate the strength of conditional and process factors as antecedents of learning possibilities. As explicated above, the theory argues that participation is a key process factor for enhancing learning possibilities (a positive outcome), but the negative outcome factor (NPR) may also be decreased by a positive experience of participating in a dialogue with the educator or in the group work discussion. It follows from the latter that, there is a positive relation to PPR and a negative relation to NPR. This means that participation in both situations links positively to positive potential for reflection (PPR) and it is assumed participation to some extent reduce the level of perceptions entailing an attitude of little value gained, of no attitude change, i.e., links negatively to negative potential for further reflection (NPR). Following from this, hypotheses $\mathrm{H} 26$ and $\mathrm{H} 27$ are added to denote an inverse linkage between the participatory constructs and negative potential for reflection-in other words, high levels of participation relate to low levels of negative outcome. Taking all of the hypotheses above together provides an operational representation of the framework and theorized factors contributing to the enhancement of learning possibilities. 


\section{Data collection and analysis}

In total, 53 indicators were formulated for development of the questionnaire used for data collection. During autumn 2010 and spring 2011, 670 students attended a digital workshop and responded individually to the (hard copy) questionnaire as soon as the workshop had ended. At ARKEN, two workshops were surveyed - the 'media and art' workshop and

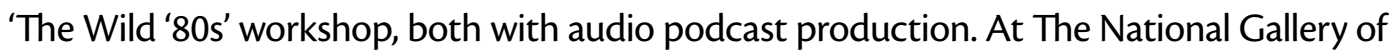
Denmark, two types of workshops were also surveyed - 'National Identity' and 'Portrait, Identity and Staging', both with still photo production. Data preparation indicated a need for preliminary analysis. In a missing value analysis, systematic non-response was found in 168 student responses across 14 workshops; these participants were, then, excluded. The resulting sample contains 502 respondents of whom 199 were students who had visited

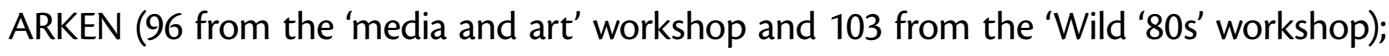
and 303 had visited The National Gallery of Denmark (137 from the 'National Identity' workshop and 166 from the 'Portrait, Identity and Staging' workshop). In total, 246 girls and 213 boys ( 43 provided no response to gender) completed the survey (mean age $=15.5$; SD age $=1.68)$.

After data preparation, exploratory factor analysis (EFA) and confirmatory factor analysis (CFA) were used sequentially in a two-step procedure to examine the internal statistical structure of items (Brown, 2006; Kline, 2010). First, a common factor analysis showed a remarkably clear pattern in which indicators (with only one exception) correlated as expected with factors as defined. By selecting the four highest-loading indicators of each factor, a statistically reliable solution with respect to the theoretical proposition of latent variables was established. However, the construct of "participation in educator dialogues" (PED) showed instability: the factor split in two, and only the items representing student reflection were statistically reliable enough to retain. This factor was, therefore, re-designated as "reflection during educator dialogues" (RED; see Table 1). This result suggests that there is not a common understanding among students that participation is one single construct; rather inner reflective thinking and verbal communicative participation are two sub-constructs of participation in an art museum education context. This finding alters the meaning of the model in that it is only the construct of reflecting during educator dialogue that is analyzed. Furthermore, five indicators did not satisfactorily reflect the construct they were argued to measure because the proportion of explained variance was too low, and these were removed from the model. In the second step, CFA was conducted to establish more solid measures, and the results are shown in Table 1.

As shown in the CFA results, a clear pattern appeared with relatively low error variance proportions, and alpha values ranging from .75 to 89 . The CFA model displayed relatively good fit with the data as indicated in most values being close to the recommended criteria for acceptable fit (recommended values in bracketed parentheses): $\mathrm{X}^{2}=1051.8,(\mathrm{p}<.0001$ $\mathrm{df}=482)[\mathrm{p}>.01$ or better $>.05], \mathrm{CMIN} / \mathrm{df}=2.18[<3], \mathrm{CFI}=.94[>.90], \mathrm{TLI}=.93$ [> .90], SRMR $=.04$ [<.10], and RMSEA $=.05$ [between .05 and .08] (Brown, 2006, p. 87). This pro- 


\begin{tabular}{|c|c|c|c|c|}
\hline Statement formulation in indicator variables and latent variable labels & & 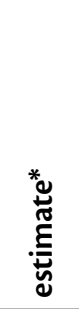 & 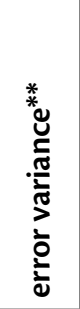 & 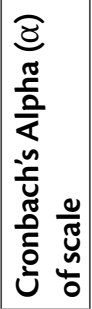 \\
\hline $\begin{array}{l}\text { It was fun to participate in the activities today } \\
\text { I had great pleasure taking part in the workshop } \\
\text { It was exciting to be here today }\end{array}$ & $\begin{array}{l}<- \\
<- \text { ENW } \\
<-\end{array}$ & $\begin{array}{l}.849 \\
.815 \\
.890\end{array}$ & $\begin{array}{l}.28 \\
.34 \\
.21\end{array}$ & .89 \\
\hline $\begin{array}{l}\text { I experienced a good mood in which all could participate } \\
\text { I felt my views were taken seriously } \\
\text { I felt that what I said was comprehended } \\
\text { I felt I was supported in having my own view of things }\end{array}$ & $\begin{array}{l}<- \\
<- \\
<- \\
<-\end{array}$ & $\begin{array}{l}.669 \\
.860 \\
.834 \\
.793\end{array}$ & $\begin{array}{l}.55 \\
.26 \\
.30 \\
.37\end{array}$ & .87 \\
\hline $\begin{array}{l}\text { I don't see what I gained from being here } \\
\text { I think I wasted my time here } \\
\text { The activities didn't mean anything to me }\end{array}$ & $\begin{array}{l}<- \\
<-A M \\
<-\end{array}$ & $\begin{array}{l}.803 \\
.849 \\
.863\end{array}$ & $\begin{array}{l}.36 \\
.28 \\
.26\end{array}$ & .87 \\
\hline $\begin{array}{l}\text { The educator had a good dialogue with us } \\
\text { The educator respected our opinions } \\
\text { The educator supported us in telling about experiences from our own life } \\
\text { I found the educator listened to what we were saying }\end{array}$ & $\begin{array}{l}<- \\
<- \text { PEDP } \\
<- \\
<-\end{array}$ & $\begin{array}{l}.682 \\
.825 \\
.689 \\
.842\end{array}$ & $\begin{array}{l}.47 \\
.32 \\
.53 \\
.29\end{array}$ & .85 \\
\hline $\begin{array}{l}\text { The artworks showed interesting things } \\
\text { The artworks captured my attention } \\
\text { I had the feeling I wanted to know more about the artworks }\end{array}$ & $\begin{array}{l}<- \\
<-A E \\
<-\end{array}$ & $\begin{array}{l}.802 \\
.840 \\
.799\end{array}$ & $\begin{array}{l}.36 \\
.29 \\
.36\end{array}$ & .85 \\
\hline $\begin{array}{l}\text { Working with digital content inspired us to use our imagination } \\
\text { Editing digital content provides freedom to shape and structure the product } \\
\text { It is engaging to work in the production process } \\
\text { The process of production provided a way to express personal views }\end{array}$ & $\begin{array}{l}<- \\
<- \text { PQMPP } \\
<- \\
<-\end{array}$ & $\begin{array}{l}.823 \\
.863 \\
.829 \\
.695\end{array}$ & $\begin{array}{l}.32 \\
.26 \\
.31 \\
.52\end{array}$ & .88 \\
\hline $\begin{array}{l}\text { I discussed the meaning of the artworks with the others } \\
\text { I developed my own opinion in the discussion with my classmates } \\
\text { I told the others about the way ar esaw the artworks }\end{array}$ & $\begin{array}{l}<- \\
<- \text { PGWD } \\
<-\end{array}$ & $\begin{array}{l}.769 \\
.654 \\
.765\end{array}$ & $\begin{array}{l}.41 \\
.57 \\
.42\end{array}$ & .78 \\
\hline $\begin{array}{l}\text { I looked at the artworks in another way after the educator explained things } \\
\text { I listened to the educator's talk about the artworks } \\
\text { I reflected further after the educator spoke about the artworks }\end{array}$ & $\begin{array}{l}<- \\
<- \text { RED } \\
<-\end{array}$ & $\begin{array}{l}.590 \\
.801 \\
.740\end{array}$ & $\begin{array}{l}.65 \\
.36 \\
.45\end{array}$ & .75 \\
\hline $\begin{array}{l}\text { My view on art has changed after today } \\
\text { I believe I have learned something meaningful about the artworks } \\
\text { I realized that I can decide for myself how I want to experience art } \\
\text { I will reflect further about the idea that art can be viewed in different ways }\end{array}$ & $\begin{array}{l}<- \\
<- \\
<- \\
<-\end{array}$ & $\begin{array}{l}.746 \\
.883 \\
.790 \\
.679\end{array}$ & $\begin{array}{l}.44 \\
.22 \\
.38 \\
.54\end{array}$ & .85 \\
\hline $\begin{array}{l}\text { I will probably not use any of the things we heard today } \\
\text { I think it was difficult to make sense of } \\
\text { I don't think I benefit from experiencing art }\end{array}$ & $\begin{array}{l}<- \\
<-N P R \\
<-\end{array}$ & $\begin{array}{l}.663 \\
.737 \\
.769\end{array}$ & $\begin{array}{l}.56 \\
.46 \\
.41\end{array}$ & .77 \\
\hline
\end{tabular}

Table 1 CFA Measurement model estimates $(N=502)$

Notes: *all estimates are standardized and significant at $p<.01$; and ${ }^{* *}$ error variance denotes the proportion of variance unexplained by the factor (e.g., .28 equals 28\%). Additionally, it should be noted that standard errors of estimates range from .039 to .104. 
vided a basis for proceeding with an estimation of the structural model of factors enhancing learning possibilities. Results are shown in Figure 2.

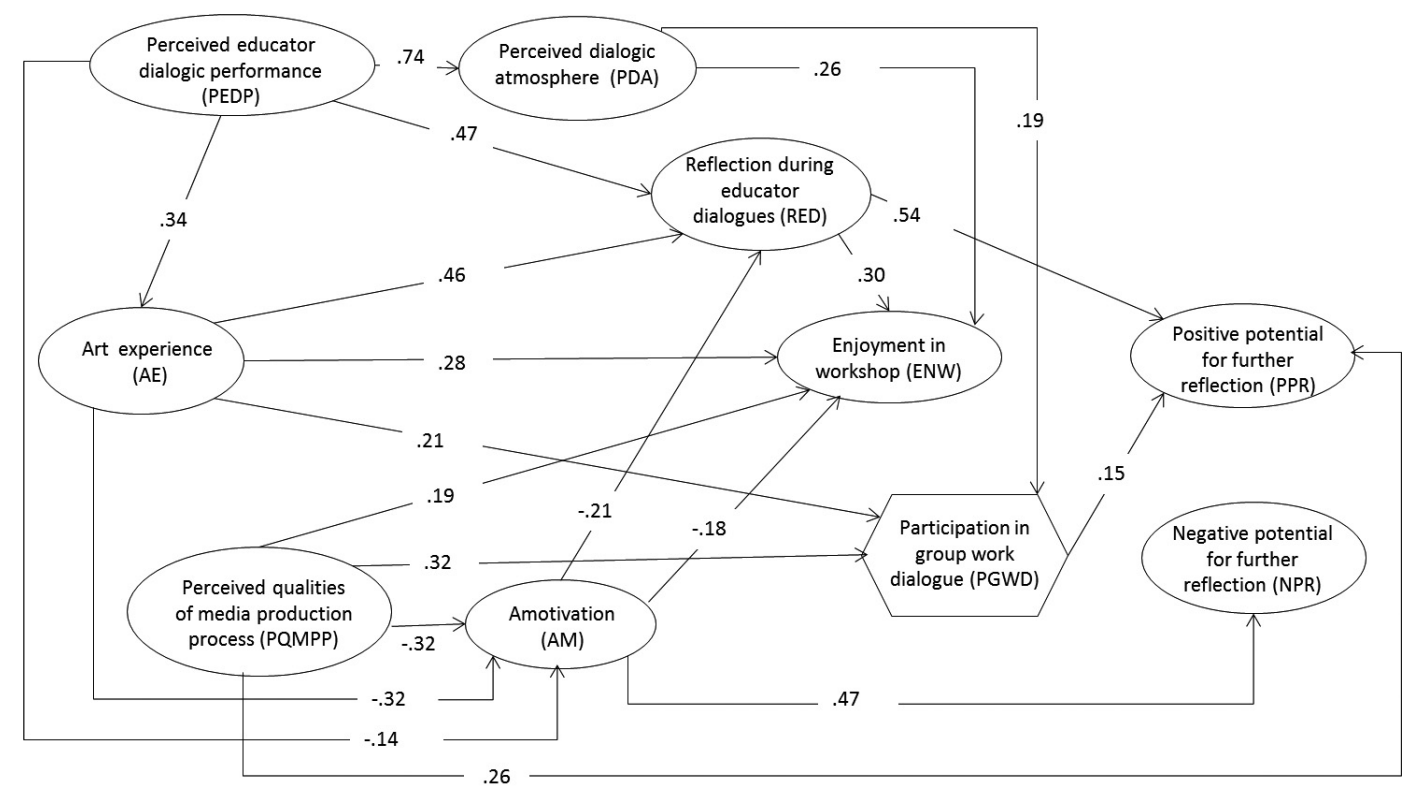

Figure 2 Estimated model of factors enhancing possibilities for learning*

* Estimates are standardized partial (beta) regression weights, and all estimates shown are significant at $p<.01$.

The fit indices of the structural model are: $X^{2}=1222.01,(p<.0001 \mathrm{df}=434)[p>.01]$, $\mathrm{CMIN} / \mathrm{df}=2.82[<3], \mathrm{CFI}=.92[>.90], \mathrm{TLI}=.91[>.90], \mathrm{SRMR}=.14$ [<.10] , and RMSEA $=.06$ [between .05 and .08] (Arbuckle, 2010; Brown, 2006, p. 87). These values are mostly above or near the cut-offs, and the model arguably fits the data reasonably well. ${ }^{2}$ The analysis proceeds by examining the beta weights, and interpretations of relationships can be assembled on the basis of each weight size, its relative size compared to other estimates of relationships and their linkages to theory. This also means that relations are estimated relatively, and the relativity of the differences of the estimates informs the interpretation of the results. Conventionally, the meaning of a partial regression in SEM is based on the following translations: 10 is weak, .25 is medium or moderate, and .4 is strong (Schumacker \& Lomax, 2010, p. 128).

\section{Results}

Overall, the model is evaluated as a feasible solution for creating an approximation of construct relations. Although 12 hypotheses were found to be insignificant, the remaining 19 
significant estimates confirm a sound and reliable explanatory model. In the following, the interpretation of the results is presented and organized around seven points:

1) Dialogic communication seems to be a powerful approach for enhancing students' learning possibilities. This is seen especially in the relations PEDP $\rightarrow$ RED beta $=.47, p<.01$ and RED $\rightarrow$ PPR beta $=.54, \mathrm{p}<.01$. These relations suggest that students who perceive the educator as respecting opinions, listening and encouraging the sharing of experiences are likely to engage in reflection during dialogues (i.e., listen to the educator, view artworks differently after the educator's talk, reflect further after this phase), which, in turn, increase the likelihood that students will acquire a positive potential for further reflection after they have left the museum. The dialogic effort of the educator is also likely to support a positive art experience (PEDP $\rightarrow$ AE beta .34, $p<.01$ ), which, in turn, seems to increase reflective thinking during the educator dialogues (AE $\rightarrow$ RED beta $.46, p<.01$ ). Furthermore, the results suggest that the dialogic performance links very strongly to students' perceptions of a positive dialogic atmosphere (PEDP $\rightarrow$ PDA beta .74, $\mathrm{p}<.01$ ).

2) Interestingly, the results suggest that a positive dialogic atmosphere (PDA) is not as important an attribute of conditions enhancing learning possibilities as expected. Perceptions of positive mood, comprehension and support for the sharing of personal experiences were not found to be that important because the relationship of perceptions of dialogic atmosphere to overall enjoyment is moderate (PDA $\rightarrow$ ENW beta .26, $p<.01$ ), and the relationship with participation in group work discussions is between weak and moderate (PDA $\rightarrow$ PGWD beta .19, $\mathrm{p}<.01$ ). This means that, although educator dialogic performance is very strongly related to students' perceptions of a dialogic atmosphere, this perception does not mediate between dialogic performance and student reflections. Apparently, the model does not support perceived dialogic atmosphere as an important factor for engaging in reflection during dialogue with the educator. It only suggests that this atmosphere is important when students participate verbally in group discussions, which is a plausible result, given that inner thoughts and reflections during the guided tour are less affected by social pressure than the articulation of one's opinions in the group work process.

3) Art experience (AE), as indicated by students' evaluation of the artworks as interesting, their attention and their wish to know more, is suggested to support reflection during the educator dialogue, as noted, along with discussions during group work processes ( $\mathrm{AE}$ $\rightarrow$ PGWD beta .21, $\mathrm{p}<.01$ ). Taking part in discussions, in turn, increases the level of positive potential for reflection (PGWD $\rightarrow$ PPR beta $.15, \mathrm{p}<.01$ ), but this is remarkably weak, which suggests a difference in strength between reflection and participation -that is, group work discussion is a much weaker factor for enhancing learning possibilities in comparison with the educator dialogue.

4) The qualities of the media production process, the result suggests, seem to enhance learning possibilities by providing a supportive framework for group discussions (PQMPP $\rightarrow$ PGWD beta .32, $\mathrm{p}<.01)$. The qualities of the media production process also seem supportive of students' overall enjoyment of the workshop (PQMPP $\rightarrow$ ENW beta .19, $p<.01$ ), 
but participating in discussions and developing opinions about art does not relate to students' overall enjoyment of the workshop. However, the qualities of the media production process seem to link directly but moderately to positive potential for reflection, as seen in PQMPP $\rightarrow$ PPR beta .26, $p<.01$. The model, therefore, suggests that, overall, digital media use is a strong factor in enhancing learning possibilities; but, as suggested, this relates to student participation in group work discussion only to a limited degree.

5) Overall enjoyment of the workshop (ENW) does not relate positively to positive potential for reflection (PPR), nor does it link negatively to negative potential for reflection (NPR). This means that, even though the results indicate that the perceptions and behavior of students may involve the state emotion of enjoyment, the overall enjoyment of the workshop does not seem to be a factor for enhancing learning possibilities. Increased likelihood of learning is linked to the activity of reflecting during the educator dialogue or in the group work discussions rather than the students' evaluation of the workshop as enjoyable.

6) Relations of amotivation seem to play an important role. Amotivation is likely to be reduced if students evaluate the educator's dialogic performance positively (PEDP $\rightarrow$ AM beta $-.14, \mathrm{p}<.01$ ), and a positive art experience similarly (but more strongly) appears to decrease levels of amotivation ( $\mathrm{AE}->\mathrm{AM}$ beta $-.32, \mathrm{p}<.01$ ). Similarly, a positive perception of the process of working with digital media seems to decrease amotivation (PQMPP $\rightarrow$ AM beta $-.32, p>.01$ ). More importantly, less amotivated students are more likely to listen, to see new things in the artworks and to think further about the themes being raised than highly amotivated students because amotivation relates moderately negatively to reflection during dialogues with the educator (AM $\rightarrow$ RED beta $-.22, p>.01$ ). These results suggest that, of the three conditional factors, art experience and perception of qualities of the media production process are the strongest conditions for reducing amotivation in that, if amotivation decreases, this will be reflected in higher levels of reflection during dialogue and higher levels of overall enjoyment of the workshop. This effect on amotivation, however, cannot be read as a corresponding to higher levels of participation in group work discussions because this relation is insignificant.

7) Amotivation also appears to link very strongly to a negative potential for further reflection (AM $>$ NPR beta .47, $\mathrm{p}<.01$ ). That is, a negative outcome is very likely to be experienced by students who cannot see what is gained, who think the activities were meaningless or that this was a waste of time (i.e., those who are highly amotivated). Remarkably, students who have no intention of using what they experienced after the workshop, do not think the workshop changed their views about art and do not think they benefit from art seem to have very strong amotivation, and none of the other constructs seem to mediate this relation. That is, the model does not support a tendency that students who participate in group work discussion or reflect during the educator dialogue are less likely to leave the museum with a negative potential for further reflection. The same is shown with respect to overall enjoyment, which has no negative relation to NPR and thus no decreasing effect. That means that the model suggest that negative outcomes, as measured in NPR, are not 
reduced by any of the other factors. A possible interpretation of this pattern may well be that the amotivation is strong and, when based on disinterest and little perceived return on investment, affords no possibilities for enhancing learning. While other factors outside the model clearly exist, this result demands attention and further inquiry into the role and function of amotivation.

\section{Discussion}

Taken together, these results provide a basis for suggesting that these selected conditional and process factors, which were empirically tested and derived from fieldwork and art educational and media theory, are important for learning in the context of digital media workshops at ARKEN and The National Gallery. The research objective was to produce a general overview of factors enhancing learning possibilities in order to inform the education departments in these museums about what conditions are especially effective. Clearly, it is possible to develop a model that is acceptable in terms of statistical criteria and which, with respect to meaning in the relational pattern, connects relatively well to the discourse of art gallery learning and digital media use in education. Construct validity can be assessed through evaluation of the internal coherence of constructs, their relationships and the meaningfulness of the estimates' relative size compared in the model. In this sense, some of the results are clearly interpretable and fit well with the theory - as shown by the fact that all significant beta weights demonstrate that hypotheses are confirmed in terms of their sign. For instance, it is shown that the assumption that conditional factors all decrease amotivation appears to be valid, and, moreover that a decrease in the level of amotivation is related to an increase in the level of reflection during educator dialogue and overall enjoyment as expected and stated in the $\mathrm{H} 20$ and $\mathrm{H} 22$.

By presenting a holistic map of all these relationships, the analysis is suggestive concerning the nature and effect of selected factors - at least, with respect to these particular workshops at ARKEN and The National Gallery Denmark. Based on the fieldwork and theoretical scrutiny, the model supports the idea that amotivation plays a significant but highly specific role in that there is no relation to participation in group work discussions (PGWD) (i.e., an inverse relation where low amotivation would relate to high levels of participation). This suggests that amotivation is caused by persistent attitudes that are difficult to alter - perhaps, relating more to a profound lack of interest in art museums. Neither overall enjoyment of the workshop nor participation in the group work discussions shows any decreasing effect; hence, amotivation links strongly to a negative potential for reflection. In this regard, David M. Mason and Conal McCarthy assert that the challenge of art museum education has to do with cultural differences, which are related to age cultures. Curatorship, visitor practice and discourse in art museums are adult culture and not youth culture (Mason \& McCarthy, 2006, p. 22). This stresses the importance of the culturally inclusive youth programs in which the two museums already invest. ${ }^{3}$ 
The results show that the dialogic approach of the educator advances learning possibilities in the sense that a relatively strong pattern of effects emerges around this behavior. Dialogic performance of museum educators is clearly important, but, interestingly, the effect is not found in the perception of a positive dialogic atmosphere. This could suggest that the students are not bothered about atmosphere, a result that conflicts with the findings of Hjort and Larsen (2003) and Bøje et al. (2005). However, because the active verbal dimension of the construct of participation is unmeasured, it still remains to be examined fully. The result that dialogic atmosphere is of less importance aligns well with the characterization of young people as responsible and knowing: Students are more decisive about their opinions and take responsibility for their learning (Illeris, 2005). Furthermore, the positive direct relation between student perceptions of qualities of media production and positive potential for reflection suggests that digital media production process has substantial value in facilitating learning experiences. This may be explained by the cultural status of digital media in young people's everyday lives, making these qualities inherently appropriate for enhancing learning possibilities. However, the weak effect of participation in group work discussion suggests more consideration is required to more strongly support the learning process in the phase of group discussions.

Methodologically speaking, it should be stressed that first of all the model analysis enforces a limited view on relations; and, therefore, the interpretation of estimates as impacts should be assessed with caution. Moreover, a critical aspect of the development of hypotheses and operational definitions was the choice of not using previously validated scales. This concern about validity and reliability, however, is not relevant in this study because of the view that constructs to an extent are specific to a group and context and because of the decision to work within the perspective of evaluating the educational strategy and, to focus on this context rather than adopting/modifying scales constructed in prior studies. Secondly, more work should be done in the analysis of latent variables and their mean differences. Once the results show support for the reliability of scales, the next steps will include tests across background variables, which will further shed light on the validity issues of the results. Although this is a limitation, the results derived from the relative estimation of relations still yield some degree of internal coherence and meaningfulness. In the future, more analytical work should include the discussion of other relevant scales used in similar contexts and groups.

\section{Conclusion}

In this study, a model of factors for enhancing learning possibilities was developed in the context of digital workshops at two large art museums. The findings suggest that the conditional factors selected for investigation relates moderately to strongly to student learning outcome as defined in positive potential for further reflection. Efforts of educators and the program features of digital media production can, thus, be argued to enable students to 
leave the museum with a changed view of art, a sense of meaningful learning and a realization that the viewer has the power to shape and design their own experience. Findings also permit an argument that, when students perceive the selected qualities of the media production process, the likelihood of acquiring a potential for further reflection is increased. Thus, planning workshops to enhance learning in students' encounters with art should consider using digital media to provide an appropriate framework within which students can discuss the meanings they find in works of art.

\section{References}

Arbuckle, J. (2010). IBM SPSS AMOS 19 User guide. Chicago: Amos Development Corporation, SPSS Inc.

Barrett, P. (2007). Structural equation modeling: Adjudging model fit. Personality and Individual Differences, 42, 815-824.

Borsboom, D. (2008). Latent variable theory. Measurement: Interdisciplinary Research \& Perspective, 6(1-2), 25-53.

Brown, T.A. (2006). Confirmatory Factor Analysis for Applied Research. New York: Guildford Press.

Buhl, M. (2005). Visual culture as a strategic approach to art production in education. International Journal of Education through Art, 1(2), 103-114.

Burton, J.M., Horowitz, R., \& Abeles, H. (2000). Learning in and through the arts: The question of transfer. Studies in Art Education, 41(3), 228-257.

Bøje, J.D., Johansen, T.G., Kampmann, J., \& Larsen, K. (2005). At lære med samtidskunst: Institut for Uddannelsesforskning, Roskilde Universitet.

Cherryholmes, C.H. (1988). Power and Criticism: Poststructural Investigations in Education. New York: Teachers College Press.

Considine, D., Horton, J., \& Moorman, G. (2009). Teaching and reading the millennial generation through media literacy. Journal of Adolescent \& Adult Literacy, 52(6), 471-481.

DeVellis, R.F. (2003). Scale Development, Theory and Application. London: SAGE Publications.

Diamantopoulos, A., \& Winklhofer, H. M. (2001). Index construction with formative indicators: An alternative to scale development. JMR, Journal of Marketing Research, 38(2), 269-277.

Diseth, Å. (2007). Students' evaluation of teaching, approaches to learning, and academic achievement. Scandinavian Journal of Educational Research, 51(2), 185-204.

Drotner, K. (2008). Leisure is hard work: Digital practices and future competencies. The John D. and Catherine T. MacArthur Foundation Series on Digital Media and Learning, 167-184.

Dysthe, O. (1999). Dialogue theory as a tool for understanding interactive learning processes. Literacy and Numeracy Studies, 9(1), 39-64.

Dysthe, O. (2002). The learning potential of a web-mediated discussion in a university course. Studies in Higher Education, 27(3), 339-352.

Dysthe, O. (2003). Sociokulturelle perspektiver på kundskab og læring. In O. Dysthe (Ed.), Dialog, samspil og laering (pp. 39-76). Aarhus: Klim.

Ellis, K. (2004). The impact of perceived teacher confirmation on receiver apprehension, motivation, and learning. Communication Education, 53(1).

Erstad, O., \& Gilje, $\varnothing$. (2008). Regaining impact: Media education and media literacy in a Norwegian context. Nordicom Review, 29(2), 219-230. 
Ganger, D.A. (2006). Teaching aesthetics and aesthetic teaching: Toward a Deweyan perspective. Journal of Aesthetic Education, 40(2), 45-66.

Gether, C., Søholt, S., Laursen, M., Tøndborg, B. Weber, C.P., \& Sattrup, L. (2010). Fremtidens Kunstmuseum. Ishøj: ARKEN Museum of Modern Art.

Goodboy, A.K., Martin, M.M., \& Bolkan, S. (2009). The development and validation of the student communication satisfaction scale. Communication Education, 58(3), 372-396.

Goodboy, A.K., \& Myers, S.A. (2008). The effect of teacher confirmation on student communication and learning outcomes. Communication Education, 57(2), 153-179.

Hjort, K., \& Larsen, L. (2003). At skabe sig selv - evaluering af projektet: Samtidskunst og unge. Roskilde.

Illeris, H. (2005). Young people and contemporary art. International Journal of Art \& Design Education, 24(3), 231-242.

Illeris, H. (2007). Pædagogik og undervisning på Statens Museum for Kunst. Working paper, Institut for pædagogisk antropologi. Retrieved February 24, 2014, from http://pure.au.dk/portal/files/67/Paedagogik_og_undervisning_P__Statens_Museum_for_Kunst.

Illeris, H. (2009). Visual events and the friendly eye: modes of educating vision in new educational settings in Danish art galleries. Museum and Society, $7(1)$.

Kember, D., Biggs, J.B., \& Leung, D.Y.P. (2004). Examining the multidimensionality of approaches to learning through the development of a revised version of the Learning Process Questionnaire. British Journal of Educational Psychology, 74(2), 261-279.

Kember, D., Leung, D.Y.P., Jones, A., Loke, A.Y., McKay, J., Sinclair, K., Tse, H., Webb, C., Wong, F.K.Y., Wong, M., \& Yeung, E. (2000). Development of a questionnaire to measure the level of reflective thinking. Assessment \& Evaluation in Higher Education, 25(4), 381-395.

Kline, R.B. (2010). Principles and Practice of Structural Equation Modeling (Third ed.). New York: Guildford Press.

Lampert, N. (2006). Critical thinking dispositions as an outcome of art education. Studies in Art Education, 47(3), 215-228.

Ledbetter, A.M., Mazer, J.P., DeGroot, J.M., Meyer, K R., Yuping, M., \& Swafford, B. (2011). Attitudes toward online social connection and self-disclosure as predictors of Facebook communication and relational closeness. Communication Research, 38(1), 27-53.

Lumby, J. (2010). Enjoyment and learning: policy and secondary school learners' experience in England. British Educational Research Journal, 37(2), 247-264.

Mason, D.D.M., \& McCarthy, C. (2006). 'The feeling of exclusion': Young peoples' perceptions of art galleries. Museum Management and Curatorship, 21(1), 20-31.

Mustapha, S.M., \& Rahman, N.S.N.A. (2011). Classroom participation patterns: A case study of Malaysian undergraduate students. International Journal for Educational Studies, 3(2), 145-158.

Pelowski, M., \& Akiba, F. (2011). A model of art perception, evaluation and emotion in transformative aesthetic experience. New Ideas in Psychology, 29(2), 80-97.

Pierroux, P., Krange, I., \& Sem, I. (2011). Bridging contexts and interpretations: mobile blogging on art museum field trips. MedieKultur: Journal of Media and Communication Research, 50, 30-47.

Rokeach, M. (1968). Beliefs, Attitudes, and Values: A Theory of Organization and Change. San Francisco: Jossey-Bass.

Rommetveit, R. (2003). On the role of "a psychology of the second person" in studies of meaning, language, and mind. Mind, Culture, and Activity, 10(3), 205-218.

Ryan, R.M., \& Deci, E.L. (2000). Intrinsic and extrinsic motivations: Classic definitions and new directions. Contemporary Educational Psychology, 25(1), 54-67. 
Schrøder, K.C., Drotner, K., Kline, S., \& Murray, C. (2003). Researching Audiences. London: Arnold Publishers, Hodder Headline Group.

Schumacker, R.E., \& Lomax, R.G. (2010). A Beginner's Guide to Structural Equation Modeling (Third ed.). New York: Routledge.

Sefton-Green, J., \& Soep, E. (2007). Creative media cultures: Making and learning beyond the school. In L. Bresler (Ed.), International Handbook of Research in Arts Education. New York: Springer.

Sinker, R. (2000). Making multimedia - evaluating young people's creative production. In J. Sefton-Green \& R. Sinker (Eds.), Evaluating Creativity - Making and Learning by Young People. London: Routledge.

Yardi, S. (2008). From multimedia to multiple voices: Conflicts in collaborative learning cultures. In K. Drotner, H.S. Jensen \& K.C. Schrøder (Eds.), Informal Learning and Digital Media (pp. 102-120). Newcastle: Cambridge Scholars Publishing.

\section{Notes}

1 See the artwork My Own Country at http://kunstonline.dk/profil/lise_harlev.php4 and the artwork A Danish Shore at http://da.wikipedia.org/wiki/J.Th._Lundbye (both accessed February 2014).

2 For more about model fit, see Paul Barrett's discussion of judging fit in SEM analyses (2007).

3 ARKEN is currently working with programs in which creative young people are helped and assisted in choices of education, and The National Gallery of Denmark has established networks and invited young people to create art in the museum.

Christian Kobbernagel Assistant Professor, Ph.D Department of Communication, Business and Information Technologies Roskilde University chko@ruc.dk 